\title{
Raw earth-based building materials: An investigation on mechanical properties of Floridia soil-based adobes
}

\author{
Monica Parlato, Simona M.C. Porto, Giovanni Cascone \\ Department of Agriculture, Food and Environment, University of Catania, Italy
}

\begin{abstract}
Raw earth, like wood and stone, is one of the oldest building materials used across the world. Nowadays, given the growing role of circular economy, researchers are ever more interested in raw earth-based building materials, because they are widely available and environmentally friendly. The use of this traditional material has positive environmental consequences, especially in traditional rural building reuse and in rural landscape preservation. In fact, raw earth is locally available and totally recyclable and, thanks to its perfect integration into the landscape, it improves site visual perception. Additives and/or chemical stabilizer agents (i.e., Portland cement) are often used in the production of raw earthbased building components in order to increase their mechanical performance and durability. This production process reduces the
\end{abstract}

Correspondence: Simona M.C. Porto, Department of Agriculture, Food and Environment, University of Catania, via S. Sofia 100, 95123 Catania, Italy. E-mail: simona.porto@unict.it

Key words: Raw earth building components; physical stabilization; mechanical tests; circular economy; sustainability.

Acknowledgements: the study was carried out by Monica C.M. Parlato $\mathrm{Ph}$.D. student of the International Doctorate in Agricultural, Food and Environmental Science of the University of Catania (Italy) and was supported by Simona M.C. Porto advisor of the $\mathrm{PhD}$ thesis and vice coordinator of the Doctorate, by Giovanni Cascone co-advisor of the $\mathrm{PhD}$ course, and by Massimo Cuomo co-advisor of the $\mathrm{PhD}$ course and responsible of the Material Testing Lab of the University of Catania (DICAR) where mechanical tests were performed; the research group thanks Guglielmino Group (Misterbianco, CT) for samples' preparation.

Funding: the research study was funded by the University of Catania through the Piano incentivi per la ricerca di Ateneo 2020-2022-Linea 2 project on 'Engineering solutions for sustainable development of agricultural buildings and land' (ID: 5A722192152), Workpackage 2 'sustainable buildings' coordinated by Simona M. C. Porto.

Conflict of interests: the authors declare no potential conflict of interests.

Received for publication: 21 January 2021.

Accepted for publication: 4 March 2021.

${ }^{\circ}$ Copyright: the Author(s), 2021

Licensee PAGEPress, Italy

Journal of Agricultural Engineering 2021; LII:1154

doi:10.4081/jae.2021.1154

This article is distributed under the terms of the Creative Commons Attribution Noncommercial License (by-nc 4.0) which permits any noncommercial use, distribution, and reproduction in any medium, provided the original author(s) and source are credited. environmental sustainability of the base material and causes a relevant increase on the embodied energy (i.e., the total energy required for the extraction, processing, manufacturing, and delivery of building components). This research work aimed at investigating how to improve the mix-design of earth-based building materials in order to increase their mechanical properties without any addition of chemical agents. A physical stabilization was performed on an original texture soil by adding various particle sizes. Mechanical tests were carried out on five different soil mixes by changing soil composition, aggregates, and water. Specimens made with mix-design 5 offered the best results in terms of flexural and compressive strength values which were $1.65 \mathrm{MPa}$ and $6.74 \mathrm{MPa}$, respectively. Mix 3 obtained the lowest linear shrinkage rate $(6.04 \%)$. Since raw earth-based materials are highly sensitive to soil composition and aggregates, this study attempted to obtain a repeatable process to produce semi-industrial adobes by optimizing and controlling various natural materials (i.e., soils, aggregates, and water).

\section{Introduction}

The rediscovery of raw earthen constructions and raw earthbased building-components is becoming an important topic in the construction sector, because raw earth is widely available and environmentally friendly. Across the world raw earth has always had a prominent place among traditional building materials throughout centuries, As stated by Houben and Guillaud (2006) one-third of the world population lives in earthen dwellings and raw earth buildings are widespread in many countries from Latin America to Africa, from Central Europe to Middle East, especially in rural areas (Avrami et al., 2008). Raw earth can be extracted and worked directly in the building site with a significant reduction of environmental costs, since no transport-related pollution is generated (Gallipoli et al., 2017). This is an important aspect to be considered in order to improve the environmental sustainability of rural building renovation or construction.

The use of raw earth has positive environmental consequences, especially in traditional rural building reuse and in rural landscape preservation. In fact, raw earth is locally available and totally recyclable and also improves the site visual perception thanks to its perfect integration into the landscape (Picuno, 2016).

Furthermore, raw earthen constructions and raw earth-based building-components offer indoor thermal and acoustic comfort as well as the capacity to absorb toxic volatile compounds (Fagone et al., 2019). In fact, due to their breathability and high thermal mass, raw earth building materials could stabilize hydrothermal indoor conditions and control temperature variation, especially during summer. Despite the aforementioned benefits from the use of raw earth materials, the development of earthen constructions is currently limited, because of the difficulties in controlling the mix design and the high vulnerability due to the washing action of rainfall. In addition, quality specifications for the technological 
process are lacking and often structures are wrongly dimensioned. Barbari et al. (2014a) proposed a simple structural calculation method in order to satisfy the minimum structural safety requirements for earthen buildings. This method is suitable especially for rural areas in developing countries 'for both the construction of buildings and the training of local technicians' (Barbari et al., 2014a).

Moreover, a weakness in the production process of raw earthbased building materials is the long time required to harden and the high manual labour cost. Some of these problems could be solved by adding aggregates to the mix design (e.g., synthetic binders, cement, and admixtures) that improve the mechanical behaviour of the earth-based building components and accelerate the hardening process (Perrot et al., 2018). Some studies reported how to apply the cement production process developed in the concrete industry to earthen construction in order to improve their performance (Giuffrida et al., 2019). Further innovative processing methods like self-compacting clays, hyper compaction and extrusion, have also been used to improve workability of raw earth building materials and reducing the curing time (Ouellet-Plamondon and Habert, 2016).

Numerous studies proposed the addition of reinforcement fibres to raw earth mix in order to improve their mechanical behaviour. Araya-Letelier et al. (2018) assessed the use of animal fibres (i.e. pig hair) in mixes. In this study, the experimental evaluation included flexural toughness, flexural and compressive strength, ultrasonic pulse velocity, drying shrinkage distributed cracking, and impact strength tests. The mechanical behaviour of adobe mixes without fibres was compared to adobe specimens reinforced with pig hair. The results of the mechanical tests showed that the addition of these fibres reduced flexural and compressive strengths. In particular the compressive strength value was 1.20 MPa for adobes with fibres and 2.02 $\mathrm{MPa}$ for adobes without fibres. On the other hand, addition of pig hair in adobe mixes increased flexural toughness and reduced drying shrinkage (Araya-Letelier et al., 2018). Statuto et al. (2018) compared the mechanical properties of adobe made with natural fibres (i.e., sheep wool and wheat straw) with those obtained without adding fibres (Statuto et al., 2018). The results showed that the compression strength values of adobes made without fibre addition was higher than in those incorporating vegetal fibres, respectively 2.05 $\mathrm{N} / \mathrm{mm}^{2}$ and $1.86 \mathrm{~N} / \mathrm{mm}^{2}$. However, the addition of animal fibres to the mix improved significantly the compression strength value, which increased to about $4.32 \mathrm{~N} / \mathrm{mm}^{2}$.

With regard to the mechanical properties of raw earth-based building components, their performance depends mainly on the correct selection of the mix design in the production process. In the study described in this paper, the mechanical properties of five different soil mixes were evaluated and compared in order to obtain best performance without adding chemical stabilizers. Therefore, the novelty of this study relies in the attempt to find an optimal mix recipe to build adobes made of a type of earthen material produced from a clay present in Sicily, traditionally used in the past for the production of bricks, and a pyroclastic sand typical of the Etna volcano area (Sicily), commonly used for mortar and concrete production (Belfiore et al., 2020).

\section{Materials and methods}

\section{Soil}

In a recent study (Giuffrida et al., 2019), five Sicilian soils were analysed in order to select the most suitable for raw earth materials. Their chemical composition, plasticity and particle size were evaluated. After these qualitative experimental analyses, a soil extracted close to Syracuse named 'Terra di Floridia' (Figure 1A) was selected, because of its higher amount of clay, easy extraction, and lower transport cost. On the basis of the plasticity test performed on the fine fraction, Floridia soil (FS) was classified as a kaolinite soil, with $47.30 \%$ liquid limit (LL), 30.68\% plastic limit (PL) and $16.62 \%$ plasticity index (PI = LL - PL).

Kaolinite soils have a limited specific surface area (about 10 $\mathrm{m}^{2} / \mathrm{g}$ ) and, therefore, have a reduced swelling and shrinkage, in both case, dry and/or wet (Gallipoli et al., 2017).

The grading of FS is shown in Figure 1B. Particle size distribution was determined through a sieve analysis carried out in accordance with the ASTM D7928-17 requirements, by using material dried in an oven at $100^{\circ} \mathrm{C}$.

FS was modified $\left(\mathrm{FS}^{\mathrm{M}}\right)$ according to an optimization procedure aimed to improve its mechanical behaviour through a physical stabilization process (Achenza and Sanna, 2009). The particle size distribution of FS was changed by adding clay, according to a ratio of $58 \%$ FS soil to $42 \%$ clay, in weight. As shown in the literature, good results were achieved with a similar soil composition

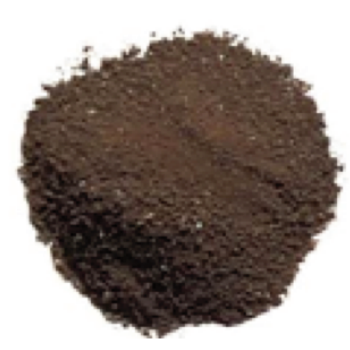

A) Floridia soil

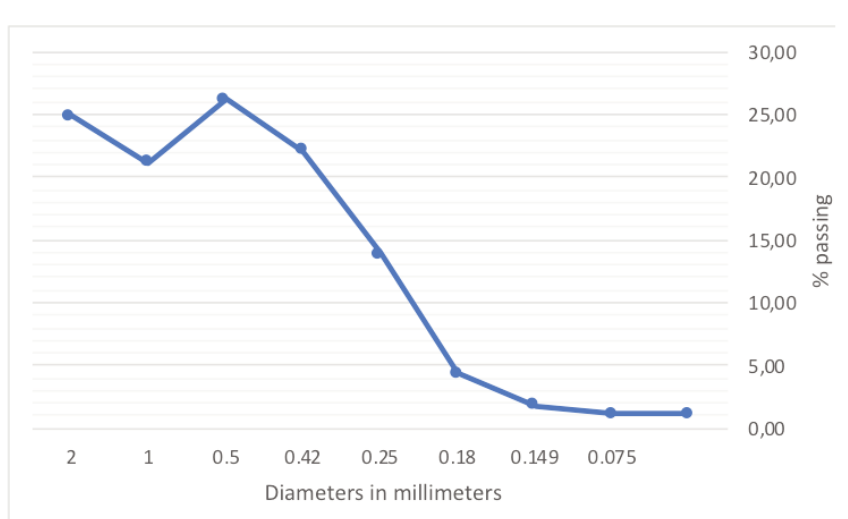

B) Grading of Floridia soil

Figure 1. A-B) Floridia soil used in the experiments. 
(Galán-Marín et al., 2013). Indeed, clay improves plasticity, mechanical characteristics and cohesion, and can reduces water absorption enhancing erosion resistance to wind and waterproofing toward capillarity water. For the purpose of preventing shrinkage and cracking problems and improving its mechanical resistance, FS and clay $\left(\mathrm{FS}^{\mathrm{M}}\right)$ were mixed with pyroclastic sand, sieved to 2 millimetres. The pyroclastic sand used is called 'azolo' and is typical of the Etna volcano area. 'Azolo' forms on the surface of lava, when glassy materials generated by the quick cooling of magma are crushed.

\section{Sample manufacturing process}

Once the material mix was ready, specimens were manually made and compacted. The process of specimen preparation started with the addition of sand, in different percentages, to $\mathrm{FS}^{\mathrm{M}}$. When the blend was completely homogeneous, water was manually added in four steps by mixing between each addition.

In accordance with the European standards (EN 1015-11:2019) for the mechanical testing of mortar, 6 prismatic samples $160 \times 40 \times 40 \mathrm{~mm}$ were prepared for each different mix. Standard steel moulds for prismatic specimens, previously moisturized to prevent adherence, were used. The specimens were cast in consecutive layers and manually compacted. Three days after the casting, specimens were demoulded and kept in an open space in dry conditions (temperature ranged between $13.1{ }^{\circ} \mathrm{C}-15.5^{\circ} \mathrm{C}$ and air humidity between $76.7 \%-80 \%$ ) for 28 days for curing before testing. This curing procedure is in accordance with the New Zealand Code (NZA 4298, 1998) and was already used in previous research, also with non-cement stabilized earth samples (Türkmen et al., 2017).

The five soil mixes reported in Table 1 were tested to assess the influence of water and sand percentages on their mechanical properties. For each mix, six repetitions were prepared. By following the same methodology for achieving physical stabilization with no addition of any chemical agent (Hall and Djerbib, 2004), soil mixes numbered 1, 2, 3, 4 and 5 were made by increasing sand percentage from $25 \%$ up to $35 \%$ and decreasing the $\mathrm{FS}^{\mathrm{M}}$ percentage, from $60 \%$ to $45 \%$. To get a consistency that could easy to work and a low total shrinkage, all samples were produced by using $20 \%$ of water and $80 \%$ of soil (FSM added with sand) except for the specimens built with mix 4 , which were made with $25 \%$ of water and $75 \%$ of soil. This increment of water was required in order to improve the workability of the mix.

\section{Mechanical resistance tests}

Since an earth-based building material is heterogeneous and anisotropic, the methodology used to carry out the mechanical tests (e.g., flexural and compressive strength) was the same as the one used for natural and artificial stone. Therefore, 30 specimens, i.e., six repetitions for each mix, were tested by conducting flexural and compressive tests according to the EN standard 1015-11:2019.

The trials started with the flexural tests on each specimen. Then, whenever a specimen failed, the two parts obtained were tested under compression. After flexural tests, the residual portions of the specimens were undamaged and suitable for compression tests, as shown in Figure 2B. Breaking loads were determined under the maximum load reached during the tests.

The flexural strength of each beam specimen was assessed by applying a single point load at the mid-span of the prismatic specimen. The test setup was mounted on the universal testing machine (UTM) by positioning the sample on two rollers (Figure $2 \mathrm{~A}$ ) with a $100-\mathrm{mm}$ wheelbase. UTM was connected with a load cell Hottinger Baldwin and load values were recorded for each specimen from the start of the test until the sample breaking under a load of $10 \mathrm{~N} / \mathrm{s}$. Data acquisition was implemented by Catman Software for Tests with Huge Channel Counts.

\section{Table 1. Soil mixes.}

\begin{tabular}{lccc} 
Soil mix ID & FSM $(\%)$ & Sand $(\%)$ & Water (\%) \\
1 & 60.00 & 20.00 & 20 \\
2 & 55.00 & 25.00 & 20 \\
\hline 3 & 50.00 & 30.00 & 20 \\
4 & 42.00 & 33.00 & 25 \\
\hline 5 & 45.00 & 35.00 & 20 \\
\hline
\end{tabular}

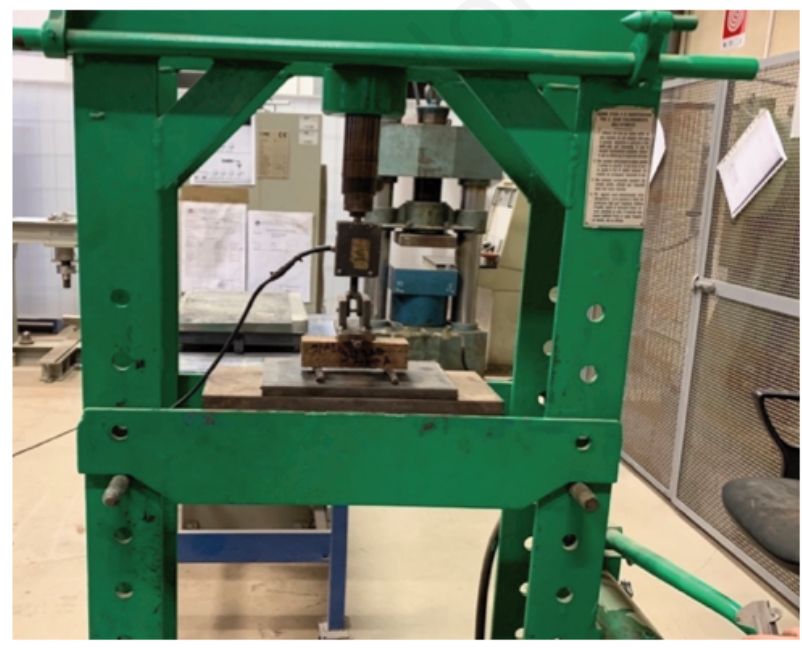

A) Flexural strength test

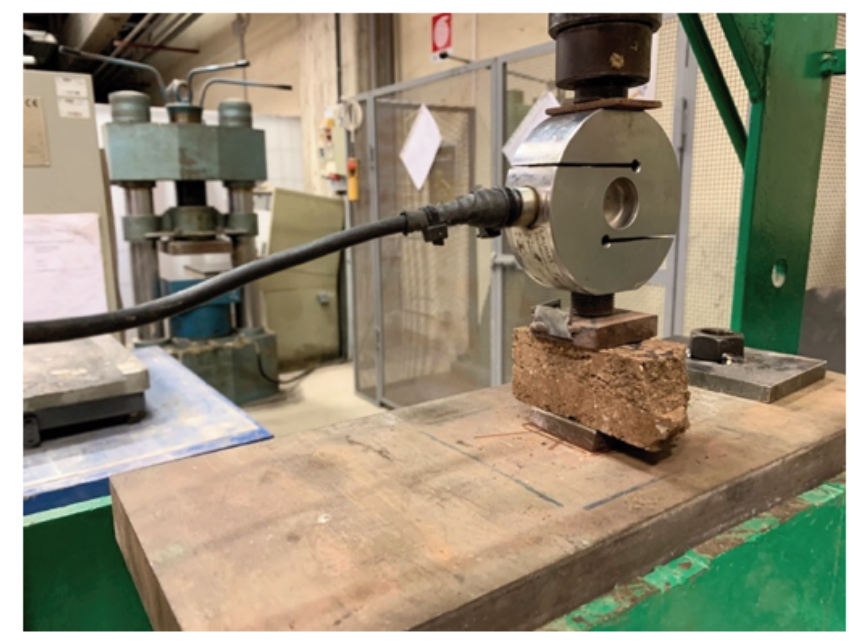

B) Compressive strength test

Figure 2. A-B) Universal Testing Machine connected with a Hottinger Baldwin Load Cell used to carry out the mechanical resistance tests. 
The flexural strength value $\left(\sigma_{f}\right)$ of each specimen was determined using Eq. (1), where $\mathrm{F}$ was the maximum applied load, L was the span between supports $(100 \mathrm{~mm}), \mathrm{b}$ was the width of the specimen at the mid-section and $d$ was the average depth of the specimen at the fracture section.

$$
\sigma_{f}=\frac{3 F L}{2 b d^{2}}
$$

The compressive strength value $\left(\sigma_{f}\right)$ was determined by Equation 2, by carrying out the compressive tests on the two remaining prismatic parts obtained after the flexural fracture of each beam specimens (Figure 2B). The samples were renamed keeping the flexural ID and adding number 1 and 2 .

$$
\sigma_{c}=\frac{F}{S}
$$

In Equation 2, $F$ was the maximum applied load and $S$ was the area of the loaded section.

During the drying process, a physical phenomenon called shrinkage occurs in the brick due to the evaporation of the moisture content. Shrinkage causes the cracking of the material due to some residual adherence of the soil to the mould and continuous and fast drying.

For earthen materials, linear shrinkage is commonly evaluated in accordance to testing method ASTM C326-09, therefore, linear drying shrinkage $\left(S_{d}\right)$ was calculated by using Equation 3,

$$
S_{d}=\frac{L_{0}-L}{L_{0}} \times 100
$$

where $L$ was the drying length of specimen after 28 days, measured by using a calibre, and $L_{0}$ was the internal length of mould (160 $\mathrm{mm})$.

\section{Results and discussion}

Flexural strength could be considered as an indicator of the capability for energy absorption. The maximum value obtained was $1.65 \mathrm{MPa}$ for soil mix 5, while the lowest was $0.89 \mathrm{MPa}$ for specimens made with soil mix 4 . This lowest value is probably due to a greater water percentage in the mix, which was $25 \%$ instead of $20 \%$. Specimens sudden showed a drop in load, because of the formation of unstable macroscopic cracks after the maximum load was reached (Figure 3).

The average of the flexural strength values calculated for each mix design are compared in Table 2 .

After the flexural failure, compressive strength tests were carried out for each part of the residual specimens. Table 3 shows the average values obtained for the 5 soil mixes. The highest value was 6.74 MPa for soil mix 5, while the lowest value was 3.05 MPa for soil mix 4. As already stated in the previously paragraph, this low value is probably due to the larger amount of water used in the mix.

The shrinkage rate for specimens of the different mixes were obtained by Equation 3. As expected, specimens made with soil mix 4 showed the highest shrinkage rate, which was equal to about $8.23 \%$. On the contrary, specimens made with soil mix 5 exhibited the lowest shrinkage rate of $6.04 \%$ (Table 4 ).

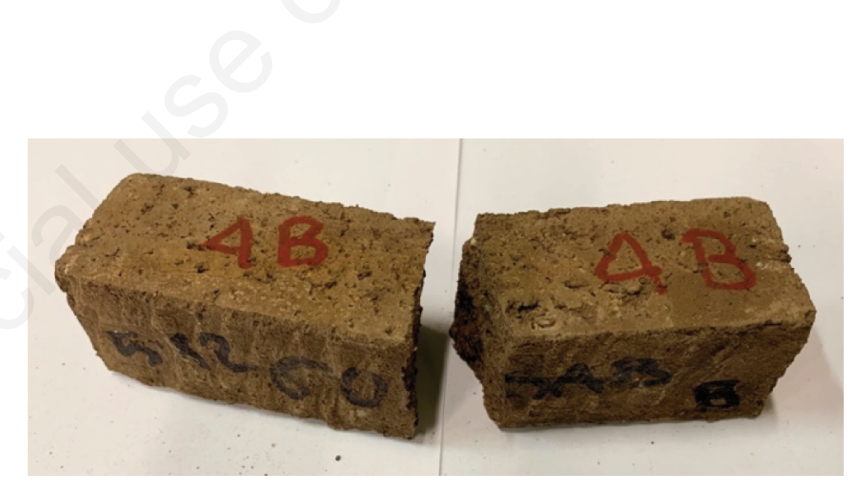

Figure 3. Failure mode of specimens.

Table 2. Average flexural strength values obtained for the five soil mixes.

\begin{tabular}{lccccc} 
Soil mix no. & Average maximum load $(\mathbf{N})$ & SD & Average flexural strength (MPa) & SD \\
1 & 411.06 & 7.97 & 1.27 & 0.28 & 0.26 \\
2 & 529.62 & 8.87 & 1.57 & 1.52 & 0.14 \\
\hline 3 & 529.95 & 5.34 & 0.89 & 0.19 \\
\hline 5 & 345.00 & 6.90 & 1.65 & 0.04 \\
\hline
\end{tabular}

SD, standard deviation.

Table 3. Average compressive strength values obtained for the five soil mixes.

\begin{tabular}{lccccc} 
Soil mix no. & Average maximum load (kN) & SD & Average dry density $\left(\mathrm{kg}^{3} \mathrm{~m}^{3}\right)$ & Average compressive strength (MPa) & SD \\
1 & 7.72 & 0.52 & 1960.00 & 4.82 & 0.32 \\
2 & 10.14 & 0.75 & 1980.00 & 6.34 & 0.47 \\
\hline 3 & 10.22 & 0.98 & 2150.00 & 6.39 & 3.05 \\
4 & 5.09 & 0.68 & 1960.00 & 0.61 \\
\hline 5 & 10.95 & 0.81 & 1960.00 & 0.43 \\
\hline
\end{tabular}

SD, standard deviation. 
The results of this study showed that compression strength values ranged between 3.05 $\mathrm{MPa}$ and $6.74 \mathrm{MPa}$. These values were above the minimum required by the most important raw earth construction international standards, such as $1.3 \mathrm{MPa}$ required by New Mexico Earthen Building Code, and 2.0 MPa imposed by New Zealand Regulation. Soil mix 5, made of $45 \% \mathrm{FS}^{\mathrm{M}}, 35 \%$ sand, and $20 \%$ water, exhibited the best upshots. In fact, the compression strength value was $6.74 \mathrm{MPa}$ and the flexural strength was 1.65 $\mathrm{MPa}$. These values were significantly higher than other results found in previous studies. Araya-Letelier et al. (2018) and Statuto et al. (2018) compared the mechanical behaviour of adobes made with and without natural fibres addition. Adobes without fibres exhibited a compression strength ranging between $2.02 \mathrm{MPa}$ and $2.05 \mathrm{MPa}$ and a flexural strength of around $0.49 \mathrm{MPa}$ (ArayaLetelier et al., 2018; Statuto et al., 2018). The highest values obtained in the trials carried out in this study are mainly due to the soil mix that incorporates a siliceous inert like 'azolo' that is commonly used in the concrete industry and provides high resistance to compression. With regard to flexural strength, it ranged between $0.89 \mathrm{MPa}$ and $1.65 \mathrm{MPa}$. Also these values are greater than the minimum required by some international code, such as the New Zealand Regulation that prescribes at least $0.25 \mathrm{MPa}$ (New Mexico, 2009; NZA 4298, 1998). All flexural strengths obtained in this study ranging between $0.89 \mathrm{MPa}$ and $1.65 \mathrm{MPa}$ were above this minimum value. Moreover, the obtained flexural strength values are less than $25 \%$ of the related compressive strength values. This was in line with other results obtained in similar studies, where flexural strength was $30 \%$ lower than compressive strength with a compressive strength multiplier of 3.5 times the flexural strength (Barbari et al., 2014b). By analysing the obtained results, it is evident that maximum loads, compressive and flexural strengths were increased for specimens with a higher quantity of 'azolo' sand. Moreover, with respect to the standard deviation of flexural strength values, specimens with a higher percentage of sand have a lower standard deviation.

Furthermore, as shown in Table 3, specimens of soil mix 5 have a low density, but exhibit the best characteristic strength. As already observed in previous studies, this means that no correlation was found between the dry density and the compressive strength of the samples (Ciancio et al., 2013). The correlation coefficient was calculated to establish the relationship between dry density and compressive strength. The result was a low correlation coefficient of $\mathrm{R}^{2} 0.14$.

As to the shrinkage rate, soil mix design 3 reached the lowest rate, which was equal to $6.04 \%$. However, the shrinkage rate was too high for all mix design compared to the acceptable values of raw earth shrinkage (Woyciechowski et al., 2017). As already demonstrated in a comparative analysis, the shrinkage rate could

Table 4. Average shrinkage rate values obtained for the five soil mixes.

\begin{tabular}{lcc} 
Soil mix no. & Average shrinkage rate (\%) & SD \\
1 & 6.98 & 0.18 \\
2 & 7.29 & 0.18 \\
\hline 3 & 6.04 & 0.36 \\
4 & 8.23 & 0.65 \\
\hline 5 & 6.25 & 0.05 \\
\hline SD, standard deviation & &
\end{tabular}

be reduced by adding both natural or artificial fibres to the mix design (Vega et al., 2011).

\section{Conclusions}

Mechanical tests were carried out on five different soil mixes by changing soil composition, aggregates, and water. The original texture of 'terra di Floridia' soil (FS) was modified by adding different particle sizes and performing only a physical stabilization on the soil. Firstly, to FS was added clay, by obtaining a soil composed of $58 \% \mathrm{FS}$ soil and of $42 \%$ clay $\left(\mathrm{FS}^{\mathrm{M}}\right)$. Afterwards, in order to improve its mechanical behaviour, a pyroclastic sand, called 'azolo', which is highly available in Etnean area, to FS ${ }^{\mathrm{M}}$. Five different mix design were tested after changing the sand percentage (from $20 \%$ to $35 \%$ ) and the water content $(20 \%$ or $25 \%$ ). Flexural and compressive strength, and linear shrinkage were evaluated. Good results were achieved for all the mechanical resistance tests, except for linear shrinkage which exhibits an excessive rate, from $6.04 \%$ to $8.23 \%$.

In order to the reduce shrinkage rate and improve ductility in the failure mode, a future research work will study the addition of natural fibres, such as sheep wool, to mix-design 5 that achieved the best results in terms of flexural and compressive strength. The reuse of this special agricultural waste as a reinforcement fibre for raw earth building materials could be relevant, as it can contribute to the environmental sustainability of the building sector (Parlato and Porto, 2020). In fact, the improvement in mechanical resistance of raw earth-based materials through the use of natural fibres, which comes from a special agricultural waste such as sheep wool, could reduce both resource consumption and environmental pollution.

\section{References}

Achenza M., Sanna U. 2009. Il Manuale tematico della Terra Cruda, Dei Tipografia del Genio Civile, Italy.

Araya-Letelier G., Concha-Riedel J., Antico F.C., Valdés C., Cáceres G. 2018. Influence of natural fiber dosage and length on adobe mixes damage-mechanical behavior. Constr. Build. Mater. 174:645-55.

Avrami E.C., Guillaud H., Hardy M. (Eds.). eds. 2008. Terra literature review: an overview of research in earthen architecture conservation. Getty Conservation Institute, Los Angeles, CA, USA.

Barbari M., Monti M., Rossi G., Simonini S., Guerri F.S. 2014a. Proposal for a simple method of structural calculation for ordinary earthen buildings in rural areas. J. Food Agric. Environ. 12:1459-63.

Barbari M., Monti M., Rossi G., Simonini S., Guerri F.S. 2014b. Simple methods and tools to determine the mechanical strength of adobe in rural areas. J. Food Agric. Environ. 12:904-9.

Belfiore C.M., Amato C., Pezzino A., Viccaro M. 2020. An end of waste alternative for volcanic ash: A resource in the manufacture of ceramic tiles. Constr. Build. Mater. 263:120118.

Ciancio D., Jaquin P., Walker P. 2013. Advances on the assessment of soil suitability for rammed earth. Constr. Build. Mater. 42:40-47.

Fagone M., Kloft H., Loccarini F., Ranocchiai G. 2019. Jute fabric as a reinforcement for rammed earth structures. Compos. Part B Eng. 175:107064.

Galán-Marín C., Rivera-Gómez C., Bradley F. 2013. Ultrasonic, 
molecular and mechanical testing diagnostics in natural fibre reinforced, polymer-stabilized earth blocks. Int. J. Polym. Sci. 2013:130582.

Gallipoli D., Bruno A.W., Perlot C., Mendes J. 2017. A geotechnical perspective of raw earth building. Acta Geotechn. 12:46378.

Giuffrida G., Caponetto R., Cuomo M. 2019. An overview on contemporary rammed earth buildings: Technological advances in production, construction and material characterization. IOP Conf. Ser. Earth Environ. Sci. 296:012018.

Hall M., Djerbib Y. 2004. Rammed earth sample production: Context, recommendations and consistency. Constr. Build. Mater. 18:281-6.

Houben H., Guillaud H. 2006. CRATerre: Traitéde Construction en Terre. Éditions Parenthèses: Marseille, France.

NMAC. 2003. New Mexico Earthen Building Materials Code. Construction Industries Division (CID) of the Regulation and Licensing Department (Santa Fe', NM).

SNZ. 1998. New Zealand Standard 4298:1998. In: Materials and Workmanship for Earth Buildings, 1998 Standards. Wellington, New Zealand.

Ouellet-Plamondon C.M., Habert G. 2016. Self-compacted clay based concrete (SCCC): proof-of-concept. J. Clean. Prod. 117:160-8.

Parlato M.C.M., Porto S.M.C. 2020. Organized framework of main possible applications of sheep wool fibers in building components. Sustain. 12:761.

Perrot A., Rangeard D., Menasria F., Guihéneuf S. 2018. Strategies for optimizing the mechanical strengths of raw earth-based mortars. Constr. Build. Mater. 167:496-504.

Picuno P. 2016. Use of traditional material in farm buildings for a sustainable rural environment. Int. J. Sustain. Built Environ. 5:451-60.

Statuto D., Sica C., Picuno P. 2018. Experimental development of clay bricks reinforced with agricultural by-products. Sustainable Farming-SFARM View project Mediterranean technology led incubator co-operation-MEDI-CUBE View project. Available from: http://atae.agr.hr/46th_ATAE_proceedings.pdf

Türkmen İ., Ekinci E., Kantarcı F., Sarıcı T. 2017. The mechanical and physical properties of unfired earth bricks stabilized with gypsum and Elazığ Ferrochrome slag. Int. J. Sustain. Built Environ. 6:565-73.

Vega P., Juan A., Ignacio Guerra M., Morán J.M., Aguado P.J., Llamas B. 2011. Mechanical characterisation of traditional adobes from the north of Spain. Constr. Build. Mater. 25: 3020-3.

Woyciechowski P., Narloch P.L., Cichocki D. 2017. Shrinkage characteristics of cement stabilized rammed earth, in: MATEC Web of Conferences. 117:00178. 